\title{
SIGNIFIKANSI PENGEMBANGAN MUTU PENDIDIKAN ARAB SAUDI
}

\author{
Didin Sirojudin*1 \\ ${ }^{1}$ Dosen Prodi Pendidikan Agam Islam Fakultas Agama Islam \\ Universitas KH. A. Wahab Hasbullah \\ mr.didinsirojudin@gmail.com \\ Waslah*2 \\ ${ }^{2}$ Dosen Prodi Pendidikan Agama Islam Fakultas Agama Islam \\ Universitas KH. A. Wahab Hasbullah \\ waslah@unwaha.ac.id
}

\begin{abstract}
A country has different challenges and problems in improving the quality of its education. Education is one of the most important aspects for the sustainability of people's lives through the means of a country's quality level of education. It can be seen that the country's quality position compared to other countries education is often used as a benchmark for progress of a country Therefore every country is competing to advance the field of education in order to achieve this progress the conditions are carried out by various countries in the world including Islamic countries, Under the influence of modern culture, the system of primary, secondary, school- vocational schools, technical schools, and arrive at university systems in the Arab and Islamic world are updated and adjusted according to western patterns as well as syllabus and curriculum preparation. The adaptation that is meant here is not to mean swallowing everything from the West, but rather an advanced western education system and form adapted to the philosophy of Islamic Education. In the national development effort, the education system is burdened with 3 objectives namely to provide at least basic education for the entire population, to prepare students with the various skills needed for economic development that is constantly changing, to educate children in beliefs, practices, Islamic values.
\end{abstract}

Keywords: Significance, Quality Development, Education

\section{A. PENDAHULUAN}

Pendidikan merupakan salah satu aspek yang sangat penting bagi keberlangsungan kehidupan masyarakat melalui sarana tingkat kualitas pendidikan suatu negara dapat diketahui posisi kualitas negara tersebut 


\section{Didin Sirojudin, Waslah.}

dibandingkan dengan negara lain pendidikan sering dijadikan sebagai tolak ukur untuk kemajuan suatu negara Oleh karena itu setiap negara berlomba-lomba memajukan bidang pendidikan dalam rangka mencapai kemajuan tersebut kondisi tersebut dilakukan oleh berbagai negara belahan dunia termasuk didalamnya adalah negara-negara Islam.

Pada awal perkembangan Islam tentu saja pendidikan Islam formal belum terselenggara pendidikan Islam yang berlangsung dapat dikatakan umumnya bersifat informal dan lebih berkaitan dengan upaya-upaya dakwah islamiyah penyebaran dan penanaman dasar aqidah dan ibadah Islam dalam kaitan itulah dapat dipahami Mengapa proses pendidikan Islam berlangsung di rumah sahabat yang paling terkenal adalah Dar al-arqam tetapi ketika masyarakat Islam telah terbentuk maka pendidikan Islam diselenggarakan di masjid proses pendidikan pada kedua tempat ini dilakukan dalam halaqah lingkaran belajar yang pada periode berikutnya berkembang menjadi madrasah ${ }^{1}$

Pada perkembangan selanjutnya pendidikan modern masuk ke wilayah timur tengah melalui pintu belakang berupa pengaruh-pengaruh budaya atau dominasi politik ia menyisihkan tradisi Islam dan menggantinya dengan tradisi barat pada semua level mulai dari tingkat dasar sampai universitas²

Lembaga-lembaga pendidikan Islam tradisional madrasah-madrasah dar Al Ulum dengan serta merta lebih menjadi semacam badan usaha yang ditempatkan

\footnotetext{
${ }^{1}$ Azyumardi Azra, Pendidikan Islam Tradisi dan Modernisassi Menuju Milenium baru Jakarta : Logos,1999 h.vii

${ }^{22}$ Belgrami, hamid Hasan, dan Ali Said Asyraf 1989 The conseft Of University terj. Machnun Husen. Yogyakarta : Tiara Wacana, 49
} 
di masjid-masjid dan di rumah rumah pribadi atau diberi bantuan alakadarnya oleh pemerintah agar lembaga-lembaga pendidikan Islam tradisional tersebut dapat tetap berdiri ${ }^{3}$

Di lain pihak sejumlah lembaga pendidikan dan sekolah yang baru dibangun dengan penampilan dan sendiri-sendiri sistem pendidikan yang baru ini membuka kesempatan kerja yang lebih luas bagi para mahasiswa di lembagalembaga pendidikan tinggi dan universitas universitas hingga pada akhirnya pemangku pendidikan di negara-negara Islam juga menentukan standar mutu dari sebuah lembaga pendidikan.

Menurut Profesor Mohamad Abdalla menyatakan institusi dan sistem pendidikan di banyak negara Islam perlu berbenah untuk meningkatkan kualitas pendidikan dan urusan mereka. ${ }^{4}$

Berdasarkan pada uraian di atas maka menarik untuk dikaji lebih mendalam terkait dengan pengembangan mutu pendidikan yang ada di negara-negara Islam.

\section{B. METODE PENELITIAN}

Metode dan jenis pengumpulan data dalam penelitian ini adalah dengan studi pustaka (library reseach) dengan mengumpulkan buku-buku, jurnal dan hasil penelitian terdahulu yang mendukung tema penelitian, diantaranya literatur tentang Pengembangan mutu Pendidikan di Arab Saudi

${ }^{3}$ Ibid

${ }^{4}$ Kritik ini disampaikan professor Mohammad Abdala,seorang ulama dan cendekiawan muslim Australia yang juga Direktur Pusat Pengajaran Dan pendidikan Islam (CITE) University of South Australia dalam diskusi bertajuk 'Islam, Knowledge, bright scholar empowerment trough education yang diselenggarakan kedutaan Australia di Jakarta, Selassa (9/5/2017) 


\section{Didin Sirojudin, Waslah.}

yang mencakup Karakteristik Mutu Pendidikan, Model Pengembangan Mutu Pendidikan di Arab Saudi. Library research mengintepretasikan data secara deskripsi analisis. Teknik analisis data penelitian ini menggunakan pendekatan deskriptif analisis. Tahapan dimulai dengan melakukan reduksi datadari sumber kepustakaan, kemudian mengorganisasi dan memaparkan data,melakukan verifikasi kemudian diakhiri dengan menyimpukan data untuk menjawab rumusan masalah. ${ }^{5}$

\section{PEMBAHASAN}

\section{a. Mutu Pendidikan}

Mutu pendidikan terdiri dari kata mutu dan pendidikan. Mutu dalam bahasa arab "hasan" artinya baik6, dalam bahasa Inggris "quality artinya mutu, kualitas"7. Dalam kamus Besar Bahasa Indonesia "Mutu adalah (ukuran ), baik buruk suatu benda; taraf atau derajat (kepandaian, kecerdasan, dsb)" 8 . Secara istilah mutu adalah "Kualitas memenuhi atau melebihi harapan pelanggan"9. Dengan demikian mutu adalah tingkat kualitas yang telah memenuhi atau bahkan dapat melebihi dari yang diharapkan, Mutu pendidikan bisadi raih dengan meanajemen yang baik, budaya disiplin, serta individu dan

\footnotetext{
${ }^{5}$ Masrukhin, MetodePenelitianKualitatif (Kudus: Media Ilmu Press, 2015), hal. 2.

${ }^{6}$ Mahmud Yunus, Kamus Arab Indonesia, (Jakarta : (Bandung : Al-Ma'arif, 1984), h. 110

${ }^{7}$ John M. Echolis, Hasan Shadily, Kamus Inggris Indonesia, (Jakarta : Gramedia, 1988) Cet. Ke XVI, h. 460

${ }^{8}$ Lukman Ali, Kamus Besar bahasa Indonesia, (Jakarta : Balai Pustaka, 1995), Cet. Ke-4, h. 677

${ }^{9}$ M.N. Nasution, Manajemen Mutu terpadu, (Jakarta : Ghalia Indonesia, 2004), Cet. ke-3, h.15
} 
stakeholder yang berkualitas. ${ }^{10}$ Pendidikan menurut Imam Al-Ghazali adalah "Sebuah wasilah untuk mencapai kemulian dan menyerahkan jiwa untuk mendekat diri kepada Tuhan". ${ }^{11}$ Berdasarkan Undang Undang Sisdiknas No. II Tahun 2003 pendidikan adalah :

Usaha sadar dan terencana untuk mewujudkan suasana belajar dan proses pembelajaran agar peserta didik secara aktif mengembangkan potensi dirinya untuk memiliki kekuatan spiritual keagamaan, pengendalian diri, keperibadian, kecerdasan, akhlak mulia, serta keterampilan yang diperlukan dirinya, masyarakat, bangsa dan Negara. ${ }^{12}$

Berdasarkan tinjauan mutu pendidikan dari segi proses dan hasil mutu pendidikan dapat dideteksi dari ciri-ciri sebagai berikut : kompetensi, relevansi, fleksibelitas, efisiensi, berdaya hasil, kredibilitas"13. Menurut Mujamil mutu pendidian adalah “Kemampuan lembaga pendidikan dalam mendayagunakan sumber-sumber pendidikan untuk meningkatkan kemampuan belajar seoptimal mungkin. ${ }^{14}$

Berdasarkan beberapa pendapat dapat disimpulkan mutu pendidikan adalah kualitas atau ukuran baik atau buruk proses pengubahan sikap dan tata laku seseorang atau kelompok orang dalam usaha mendewasakan

\footnotetext{
${ }^{10}$ Arja Haapakorpi, assurance Processes in Finnish Universities. Jurnal Quality in education Vol.17 no.1 tahun 2011.hal 70-82

${ }^{11}$ Muhammad Utsman el-Muhammady, Pemurnian Tasawuf oleh Imam Al-Ghazali,www/ Scribd/com/doc/2917072/ tgl. 19 April 2019

${ }^{12}$ Tim Redaksi Sinar Grafika, Undanng-Undang Sisdiknas 2003, (Jakarta : Sinar Grafika, 2007), h. 2

${ }^{13}$ Moch Idochi Anwar, Op. Cit., h. 19

${ }^{14}$ Mujamil Qomar, Op. Cit., h. 206
} 


\section{Didin Sirojudin, Waslah.}

manusia untuk mendekatkan diri kepada Tuhan melalui upaya bimbingan pengajaran dan pelatihan. Mutu di bidang pendidikan meliputi mutu input, proses, output, dan outcome. Input pendidikan dinyatakan bermutu jika siap berproses. Proses pendidikan bermutu apabila mampu menciptakan suasana Pembelajaran yang Aktif, Kreatif, dan Menyenangkan.

\section{b. Karakteristik Mutu Pendidikan}

Mutu pendidikan diukur secara universal baik dari segi input, proses, output maupun outcome. Aada 13 karakteristik yang dinilai dalam hal mutu pendidikan yaitu :
a. Kinerja (performan).
b. Waktu wajar (timelines)
c. Handal (reliability).
Data tahan (durability)
e. Indah (aesteties).

f. Hubungan manusiawi (personal interface).

g. Mudah penggunaanya (easy of use).

h. Bentuk khusus (feature).

i. Standar tertentu (comformence to specification).

j. Konsistensi (concistency).

k. Seragam (uniformity).

1. Mampu melayani (serviceability). 
m. Ketepatan (acuracy $)^{15}$.

Kinerja (performan) berkaitan dengan aspek fungsional sekolah yang terdiri dari kinerja guru dalam mengajar. "Guru merupakan salah satu pelaku dalam kegiatan sekolah. Oleh karena itu ia dituntut untuk mengenal tempat bekerjanya itu. Guru perlu memahami faktor-faktor yang langsung dan tidak langsung menunjang proses belajar mengajar"16. Waktu wajar (timelines) yaitu sesuai dengan waktu yang wajar meliputi memulai dan mengakhiri pelajaran tepat waktu, waktu ulangan tepat. Handal (reliability) yaitu usia pelayanan bertahan lama. Meliputi pelayanan prima yang diberikan sekolah menjadi prinsip agar pihak yang dilayani merasa senang dan puas atas layanan yang diberikan sehingga menjadi pelanggan yang baik dan setia. Hal ini sesuai dengan sikap kaum Ansor dalam menerima kuam Muhajirin yang diabadikan dalam Al-Qur'an surat Al-Hasyr ayat 9 :

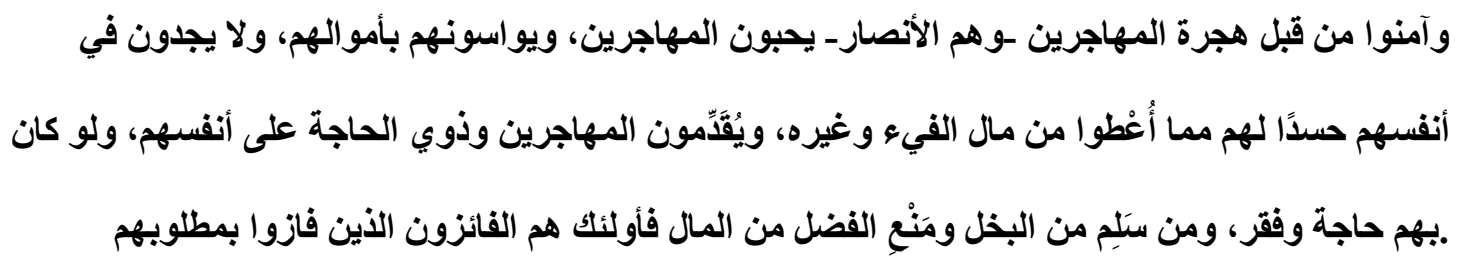

Artinya :

Dan orang-orang yang telah menempati kota Madinah dan telah beriman (Ansor) sebelum (kedatangan) mereka (Muhajirin), mereka (Ansor) 'mencintai' orang yang berhijrah kepada mereka (Muhajirin). dan mereka (Ansor) tiada menaruh keinginan dalam hati mereka terhadap apa-apa yang diberikan kepada mereka (Muhajirin); dan mereka mengutamakan (orang-orang muhajirin), atas diri mereka sendiri, Sekalipun mereka dalam kesusahan. dan siapa yang dipelihara dari kekikiran

\footnotetext{
${ }^{15}$ Husaini Usman, Manajemen Teori, Praktek Dan Riset Pendidikan, ( Jakarta : Bumi Aksara, 2006), h. 411

${ }^{16}$ Soetjipto, Raflis Kosasi, Profesi Guru, (Jakarta : renika Cipta, 2000), Cet. Ke-1, h.146
} 


\section{Didin Sirojudin, Waslah.}

dirinya, mereka Itulah orang orang yang beruntung17. Isi kandungan ayat tersebut diantaranya yaitu (1) Adanya usaha menghormati orang lain ( kaum Muhajirin), (2) Kerelaan kaun Ansor apa yang diberikan kepada kaum Muhajirin, (3) Kaum Ansor mengutamakan penghormatan kepada kaum Muhajirin, (4) Kaum Ansor rela mengalahkan kepentingan sendiri. Isi kandungan ayat tersebut dapat diterapkan dalam dunia pendidikan dengan menerapkan manajemen layanan pendidikan dalam mencapai mutu pendidikan yang berakhlak.

Daya tahan (durability) yaitu tahan banting, misalnya meskipun krisis moneter, sekolah masih tetap bertahan. Indah (aesteties) misalnya eksterior dan interior sekolah ditata menarik, guru membuat media-media pendidikan yang menarik. Hubungan manusiawi (personal interface) yaitu menjunjung tinggi nilai-nilai moral dan profesionalisme. Hal ini bisa dicapai apabila terjalin komunikasi yang sehat. “Dari komunikasi itu bisa diperoleh suasana yang akrab dan harmonis, bahkan bisa mendamaikan dua pihak yang bertikai"18. Mudah penggunaanya (easy of use) yaitu sarana dan prasarana dipakai. Misalnya aturan-aturan sekolah mudah diterapkan, buku-buku perpustakaan mudah dipinjam dikembalikan tepat waktu. ${ }^{19}$

Bentuk khusus (feature) yaitu keuggulan tertentu misalnya sekolah unggul dalam hal penguasaan teknologi informasi (komputerisasi). “Persyaratan pertama bagi kepemimpinan pengajaran adalah guru hendaknya memiliki visi mengenai unggulan dalam mengajar"20. Standar tertentu

\footnotetext{
${ }^{17}$ Mahmud Yunus, Terjemah Al-Qur'an Al-Karim, (Bandung : Al-Ma'arif, 1984), h. 493

${ }^{18}$ Mujamil Qomar, Op. Cit., h. 251

${ }^{19}$ Waslah. "Manajemen Madrasah Bertaraf Internasional Amanatul Ummah Pacet Mojokerto", dalam Jurnal Dinamika : Jurnal Kajian Pendidikan dan Keagamaan, Vol. 3, no. 1, 87-96, 2018.

${ }^{20}$ Cyril Poster, Gerakan Menciptakan Sekolah Unggulan, (Jakarta : Lembaga Indonesia Adidaya, 2000), Cet. Ke1, h. 101
} 
(comformence to specification) yaitu memenuhi standar tertentu. Misalnya sekolah tetlah memenuhi standar pelayanan minimal. Konsistensi (concistency) yaitu keajegan, konstan dan stabil, misalnya mutu sekolah tidak menurun dari dulu hingga sekarang, warga sekolah konsisten dengan perkataanya. Seragam (uniformity) yaitu tanpa variasi, tidak tercampur. Misalnya sekolah melaksanakan aturan, tidak pandang bulu, seragam berpakaian. Mampu melayani (serviceability) yaitu mampu memberikan pelayanan prima. Misalnya sekolah menyediakan kotak saran dan saran-saran yang masuk mampu dipenuhi dengan baik sehingga pelanggan merasa puas. Ketepatan (acuracy) yaitu ketepatan dalam pelayanan sesuai dengan yang diinginkan pelanggan sekolah.

\section{c. Model pengembangan mutu pendidikan di Arab Saudi}

Adapun terkait model pengembangan mutu, bagaimanakah yang baik dan tepat kiranya untuk bisa untuk mendongkrak kualitas mutu pendidikan nasional kita saat ini, Quality award seringkali dipakai untuk melakukan self

assasement. Organisasi dapat memanfaatkan elemen-elemen dalam Quality Award untuk mengukur kemajuan dari implementasi manajemen kualitas. Harjono menerangkan terdapat tiga model quality award yang secara luas di adopsi oleh perusahaan didunia untuk melakuakan pengukuran atau evaluasi 


\section{Didin Sirojudin, Waslah.}

diri, yaitu Deming Prize, Malcolm Balridge National quality, European quality award. ${ }^{21}$

Untuk mengetahui model sistem pengembangan mutu pendidikan di Negara Islam agar lebih fokus di sini Penulis mengambil negara yang mayoritas penduduknya beragama Islam yaitu:

\section{a. Arab Saudi}

Arab Saudi mencakup sebagian besar Semenanjung Arab dari luas Semenanjung Arab yang mencapai kurang lebih 3 juta kilometer persegi 2.200.000 kilometer persegi merupakan daerah Arab Saudi, negara ini berbatasan dengan teluk Persia Qatar dan negara persatuan Emirat Arab di sebelah timur dengan negara Oman dan Yaman di Selatan laut merah dan teluk aqaba di sebelah barat dan dengan Jordan Irak dan quait di sebelah utara Arab Saudi berpenduduk kurang lebih 21.504.613 jiwa 43\% di antaranya berusia di bawah 15 tahun dan 2,5\% berusia di bawah 65 tahun ${ }^{22}$

Nama resmi negara ini adalah kerajaan Saudi Arabia ( the Kingdom of Saudi Arabia) yang berdiri pada tahun 1932 awal lahirnya negara ini ketika Abdul Azeez Ibn Abdur-Rahman Al Saud dan Sultan Najd dan pengikutnya

\footnotetext{
${ }^{21}$ Retno wilan damayanti:Quality award untuk menngevaluasi Pencapaian Implementasi Manajemen KualitasPerusahaaan. Jurnal Peforma Vol.7 No.1 tahun 2008. Hal.55-70

${ }^{22}$ Agustiar Syah Nur, Perbandingan Sistem Pendidikan 15 Negara( Bandung: Lubuk Agung:2001)h.39
} 
menyatukan kedua bagian negaranya dibawa satu administrasi dan satu nama kata Saudi itu sendiri berasal dari nama rumah saud yang berkuasa. ${ }^{23}$

Arab Saudi secara resmi dikenal sebagai kerajaan Arab Saudi adalah negara Arab terbesar di Asia Barat dengan luas lahan dan terbesar kedua di dunia Arab Arab Saudi memiliki cadangan minyak terbesar di dunia yang sebagian besar terkonsentrasi di provinsi Jawa Timur minyak penyumbang lebih dari 95\% ekspor dan 70\% dari pendapatan pemerintah meskipun bagian dari ekonomi non minyak telah berkembang baru-baru ini ini telah memfasilitasi transformasi kerajaan gurun belakang menjadi salah satu negara terkaya di dunia keadaan ini menjadikan Arab Saudi sebagai negara yang memberi pendidikan gratis kepada seluruh siswa baik yang berasal dari dalam negeri maupun yang berasal dari negara lain

Pada tanggal 23 September 1932 Abdul Aziz Bin Abdurrahman Al Sa'ud memproklamasikan berdirinya Kerajaan Arab Saudi (Al-mamlakah AlArabiyah Al-su'udiyah) dengan menyatukan wilayah Riyard, Najd (nenek), Ha-a, Asir, dan hijaz. Abdul Aziz kemudian menjadi raja pertama pada Kerajaan tersebut dengan demikian dapat dipahami nama Saudi berasal dari kata nama keluarga Raja Abdul Aziz Al Saud Arab Saudi terkenal sebagai negara kelahiran Nabi Muhammad SAW serta tumbuh dan berkembangnya agama Islam sehingga pada benderanya terdapat dua kalimat syahadat yang

\footnotetext{
${ }^{23}$ Komisi Nasional Mesir untuk UNESCO,Sumbangan Islam Kepada Ilmu dan kebudayaan (Bandung:Pustaka,1997)h.46
} 


\section{Didin Sirojudin, Waslah.}

berarti tidak ada Tuhan yang pantas untuk disembah melainkan Allah dan Nabi Muhammad adalah utusan Allah

Masyarakat Arab sebelum Islam disebut masyarakat jahiliyah masyarakat jahiliyah menurut Philip K hitti adalah suatu masyarakat yang dikenal dengan masa kebodohan ketidaktahuan atau kebiadapan pada pada saat itu masyarakat Arab tidak pandai baca tulis mereka juga memeluk agama watsani yang bertuhankan kepada banyak berhala serta dikenal dengan perilaku kasar bermoralitas rendah. ${ }^{24}$

Menurut moenir mursi pendidikan di negeri negeri Arab sebelum Islam dilaksanakan melalui peniruan dan cerita anak-anak kecil tumbuh dan berkembang dengan meniru dan mendengar hikayat orang-orang dewasa suatu kabilah dan keluarga mengajarkan nilai-nilai yang sesuai dengan prinsip-prinsip dan nilai-nilai kemasyarakatan yang berlaku dalam kabilahnya kaum Arab mengekspresikan dan membanggakan nilai-nilai kemasyarakatan dalam kabilahnya melalui syair-syair. ${ }^{25}$

Untuk mengubah perilaku jahiliyah bangsa Arab maka Allah Yang Maha bijaksana mengutus seorang rasul yaitu Muhammad SAW Rasulullah SAW adalah seorang hamba Allah yang berhiaskan budi pekerti yang luhur dan terpuji, beliau sangat terkenal di kalangan masyarakat Quraisy sebagai ksatria selalu teguh dan tepat Memegang janji orang yang baik dengan

\footnotetext{
${ }^{24}$ Philip K Hitti, History Of the Arab, (London: The Macmilan Press LTD,1974)h.87

${ }^{25}$ Muhammad Munir Mursy Ushuliha wa Tatahwuriha fi al-Bilad al-Arabiyyat Al-Qohirah: 'Alim al-Kubt, Jurnal al-Tarbiyyat la-Islamiyyat: Vol.20. No 1 Tahun 2013.hal.21-40
} 
tetangga dan sangat santun dan orang yang selalu menjauhkan diri dengan perbuatan yang tidak baik rendah diri atau tawadu Dermawan pemberani jujur dan terpercaya sehingga mereka menyebutnya Al Amin atau yang sangat jujur dan dipercaya. ${ }^{26}$

Pendidikan pada masa Rasulullah SAW sesuai dengan kondisi sosial politik pada masa itu dapat dibagi menjadi dua periode yaitu periode Mekkah dan periode Madinah dengan melihat karakteristik perkembangan pendidikan Islam maka periode Mekah dapat dibagi tiga tahapan sesuai dengan tahapan dakwah yang dilakukan Rasulullah SAW di Mekah (1) tahapan sembunyi atau perorangan (2) tahapan terang-terangan dan (3) tahapan seruan umum materi pendidikan Islam sewaktu Nabi Muhammad SAW di Madinah adalah memperdalam dan memperluas materi yang pernah diajarkan di Mekah²7

Pendidikan Islam yang bermula mula dilakukan sekolah yang bernama kuttab yang mengajarkan isi buku suci Alquran sastra Arab pokok-pokok gramatika dan berhitung diajarkan oleh guru-guru yang disebut Mualim dari zaman permulaan itu dikenal peristiwa tawanan perang Badar yang dibebaskan kalau mereka mau dan sanggup mengajar menulis dan membaca Disamping itu masjid juga menjadi tempat belajar Selain tempat beribadah salah satu fungsi masjid ialah tempat sembahyang Jumat khotbah Jumat itu sebenarnya telah memberi pendidikan untuk umum

\footnotetext{
${ }^{26}$ Ramayulis,Ilmu Pendidikan Islam,(Jakarta:kalam Mulia,2011),h.17

${ }^{27}$ Ramayulis, Ilmu Pendidikan...h.35
} 


\section{Didin Sirojudin, Waslah.}

Dimana-mana merupakan tempat memberi pendidikan umum sejak dahulu perpustakaan pun turut menjadi tempat memberi pendidikan karena kepala perpustakaan biasanya adalah ahli sastra atau filsafat raja-raja dan Sheikh mendatangkan guru agama ke istananya untuk mengajar anakanaknya dan kaum keluarganya serta orang di lingkungan yang terdekat kadang-kadang rumah Sheikh atau guru agama pun menjadi tempat pendidikan yang dikunjungi orang untuk mempelajari ilmu dari Sheikh dan guru itu. ${ }^{28}$

Dewasa ini tempat belajar itu disebut Madrasah keadaan pendidikan di Arab tidak berkembang pesat seperti di Baghdad dan Mesir yang mengalami persentuhan dan akulturasi dengan kebudayaan bangsa lain dalam abad ke-18 timbul aliran Wahabi yang digerakkan oleh Muhammad bin Abdul Wahab untuk memurnikan agama Islam dari kesalahan-kesalahan yang terjadi dalam waktu itu dan gerakan itu mendapat bantuan dari Ibnu Saud pendidikan yang dilakukan seperti di atas berjalan sampai pada pertengahan abad ke-20 ini dibentuk 1 Direktorat di ibu kota 4 provinsi Arab Saudi dibentuk jawatan pendidikan yang mengatur pendidikan dalam provinsi itu salah satu dari deret itu ialah Direktorat Pendidikan wanita wanita belum mendapat pendidikan dianggap perlu ada 1 Direktorat khusus yang mengusahakan supaya kamu wanita terdorong bersekolah dan mendapat tempat di sekolah

\footnotetext{
${ }^{28}$ Imdadun rahman, Arus baru radikal Islam:Tranmisi Revivalisme Islam Timur tengah ke Indonesia,(Jakarta: Erlangga,2009),h.56
} 
Pendidikan telah menjadi perhatian utama di Arab Saudi semenjak unifikasi negeri ini tahun 1932 dan khususnya semenjak tahun 1954 ketika Kementerian Pendidikan dibentuk Pada tahun 1964 Raja Faisal Ibn Abd Aziz memegang tampuk pemerintahan menggantikan ayahnya Abd Aziz pada masa inilah diadakan pembaharuan di dalam bidang pendidikan pendidikan secara besarbesaran disediakan bagi laki-laki dan perempuan mulai dari taman kanakkanak sampai Universitas mahasiswa militan diberi beasiswa untuk studi spesialis dan Institut Institut internasional orang tua siswa yang kurang mampu membiayai sekolah anaknya dibantu oleh Negara pemerintah Saudi Arabia mengambil slogan free education for all dan dijadikan kebijakan yang permanen, Di samping kejuruan seperti sekolah-sekolah industri sekolah dagang kedokteran jumlah mahasiswa yang dikirim ke luar negeri setiap tahun bertambah juga adanya penambahan jumlah universitas universitas.

Pada tahun 2005 Raja Abdullah diangkat sebagai raja dia mulai gencar melakukan pembaruan khususnya di bidang pendidikan dimana pada saat awal tahun 2005 tidak ada satupun universitas di Arab Saudi yang masuk dalam ranking Universitas dunia namun di tahun 2011 King Saud University universitas tertua di Arab Saudi sudah masuk dalam ranking 200 besar dunia (20 besar Asia) mengalahkan seluruh universitas di Indonesia.

Hal ini tentu tidak lepas dari langkah pembaharuan di bidang pendidikan oleh raja Abdullah melalui anggaran pendidikan yang mencapai 


\section{Didin Sirojudin, Waslah.}

27\% dari total anggaran belanja Arab Saudi Raja Abdullah memberikan beasiswa kepada pemuda-pemudi Arab Saudi untuk belajar ke luar negeri baik ke barat maupun ke timur Amerika Inggris Australia Jepang Malaysia dan negara-negara tujuan pemuda-pemuda Saudi untuk menuntut ilmu.

Raja Abdullah juga mengirimkan guru dan dosen ke Amerika untuk Belajar sains dan manajemen selain mengirimkan para pemuda dan pelajar nya ke luar negeri Raja Abdullah juga mengundang ilmuan-ilmuan dunia untuk berkiprah dan berpartisipasi dalam membangun SDM di Arab Saudi lebih dari 15 peraih Nobel dari berbagai bidang disiplin ilmu telah didatangkan dan dikontrol secara khusus oleh universitas-universitas di Arab Saudi untuk transfer ilmu pengetahuan Selain itu program visiting Professor dan postdoctoral juga mampu mewarnai dunia akademik di Arab Saudi.

Sampai sekarang di bawah kerajaan Salman bin Abdul Aziz Al Saud pendidikan di Arab Saudi masih menjadikan banyak minat untuk menuntut ilmu di sana Apalagi ilmu agama yang merupakan ilmu yang berkembang di Arab Saudi siswa internasional akan menemukan lingkungan yang ramah di Arab Saudi dan pemerintah bahkan menyediakan program beasiswa khusus untuk mahasiswa non Saudi .

Arab Saudi adalah salah satu tempat terbaik di dunia untuk program Master dalam studi Islam. Belajar di negara ini juga menyediakan pencelupan budaya dan bahasa Arab penuh bagi siswa tidak dari Timur Tengah atau non 
penutur asli Arab. Selain studi Islam, lembaga Saudi modern yang menyediakan berbagai macam program gelar master dalam seni, ilmu pengetahuan, teknik, pertanian, kedokteran, pendidikan, ilmu komputer dan ilmu informasi. banyak Program gelar master yang diajarkan dalam bahasa Inggris, terutama di bidang teknis seperti teknik. Walaupun dalam praktiknya badan yang mengelola pendidikan di Arab Saudi beragam dan independen antara yang satu dengan yang lainnya . Namun rencana dasar program-program pendidikan hampir sama.

Sekolah dasar terdiri dari 6 tahun yang dimulai setelah anak berusia 6 tahun sesudah itu Sekolah Menengah Pertama selama 3 tahun diikuti 3 tahun sekolah menengah tingkat atas siswa yang melanjutkan pendidikannya ke tingkat pendidikan tinggi memerlukan rata-rata 4 tahun untuk mendapatkan Sarjana Muda dalam bidang ilmu ilmu sosial atau Seni atau rata-rata 5 tahun untuk sarjana muda bidang ilmu-ilmu eksakta ${ }^{29}$.

Pada pendidikan dasar anak-anak mulai masuk sekolah pada usia 6 sampai 12 tahun kurikulum atau mata pelajaran yang ada di pendidikan dasar adalah sebagai berikut: bahasa Arab, pendidikan seni, geografi, sejarah, ekonomi rumah ( untuk anak perempuan), matematika , pendidikan jasmani ( untuk anak laki-laki), studi Islam dan sains . sertifikat : syahadat Al madaris Al ibtida iyah ( umum elementary school certificate).

${ }^{29}$ Agustiar syah Nur Op.Cit, h.42 


\section{Didin Sirojudin, Waslah.}

Sedangkan pada pendidikan menengah anak-anak mulai masuk sekolah pada usia 12 sampai 14 tahun kurikulum yang ada di pendidikan menengah adalah sebagai berikut bahasa Arab pendidikan seni geografi sejarah ekonomi rumah untuk anak perempuan matematika pendidikan jasmani untuk anak laki-laki studi Islam dan sains dan bahasa tambahannya adalah bahasa Inggris sertifikat syahadat Al Kahfi kafa'ad Al mutawassitah (Intermediate School Certificate).

Pendidikan lanjutan (secondary education) terdiri dari:

\section{a. Pendidikan lanjutan umum}

Durasi 3 tahun umur 15 sampai 18 tahun pelajaran wajib selama tahun pertama mendapatkan pelajaran umum yang sama 2 tahun terakhir dibagi menjadi sains dan sosial atau literasi siswa yang mempunyai 60\% atau lebih boleh memiliki keduanya sedangkan yang kurang dari 60\% dan memilih sosial pelajaran umum bahasa Arab biologi kimia bahasa Inggris grafis secara ekonomi rumah tangga khusus perempuan matematika pendidikan fisika khusus laki-laki dan pendidikan agama

\section{b. Pendidikan lanjutan agama}

Durasi 3 tahun atau umur 15 tahun dan literatur bahasa kebudayaan umum geografi secara pendidikan agama

\section{c. Pendidikan lanjutan teknik}

ada tiga tipe pendidikan lanjutan teknik yaitu teknikal komersial dan Agri 
kultural, durasi 3 tahun atau umur 15 sampai 18 tahun kurikulum tiga tipe lanjutan teknik yaitu satu teknik yaitu gambar arsitektur otomotif elektrikal mekanikal mesin mekanik a metal radio televisi dengan pelajaran tambahan bahasa Arab kimia bahasa Inggris matematika pendidikan fisika fisika dan pendidikan agama 2 komersial yaitu bahasa Arab akuntansi pembukuan korespondensi komersial ekonomi bahasa Inggris matematika ekonomi matematika umum geografi manajemen dan sekretariat Andan pendidikan agama 3 agrikultural yaitu ekonomi agrikultural agronomi perkembangan hewan biologi terapan kimia terapan matematika terapan fisika terapan bahasa Arab bahasa Inggris manajemen pertanian dan lahan holtikultura pendidikan agama pemasaran dan nutrisi pangan .

Dan juga tersedia pendidikan khusus menghafal al-quran di jenjang Sekolah Dasar Sekolah Menengah Pertama dan sekolah menengah atas dan juga pendidikan industri perdagangan dan pertanian pendidikan umum diawasi oleh kementerian pendidikan dan pengajaran Arab Saudi sementara pendidikan tinggi diawasi oleh kementerian pendidikan tinggi Arab Saudi.

Pada tahun 1424 Hijriah atau 2003-2004 telah keluar peraturan baru yakni ujian kemampuan untuk seluruh siswa kelas akhir di tingkat Sekolah Menengah Atas yang diadakan di universitas-universitas oleh pusat standarisasi dan perkembangan Arab Saudi tes tersebut mengukur bidang kebahasaan dan olahragaan Selain itu bagi para siswa yang akan melanjutkan studinya di bidang kedokteran atau teknik 


\section{Didin Sirojudin, Waslah.}

diwajibkan untuk mengikuti ujian prestasi dengan 5 mata pelajaran yaitu matematika Kimia Fisika bahasa Inggris dan biologi pada tahun 1434 hijriah atau 2012-2013 mata pelajaran bahasa Inggris dihapus dari ujian prestasi tersebut .

Sejak beberapa tahun terakhir pemerintah Arab Saudi juga membuat program pelayanan 2 tanah suci untuk beasiswa ke luar negeri yakni program besar dan ambisius yang bertujuan untuk mengembangkan bakat warga negara Arab Saudi dengan mengirimkan warga ke universitas universitas di berbagai belahan dunia program ini sudah diikuti oleh 10 ribu penerima beasiswa.

Pendidikan bagi anak-anak wanita Arab Saudi dikelola secara khusus oleh suatu badan yaitu generall administration of girl education (GAGE) yang dibentuk pada tahun 1960 pendirian sekolah sekolah khusus bagi anak-anak wanita tertunda karena adanya rasa keberatan dari sebagian orang tua dan ulama yang beranggapan bahwa pendirian sekolah sekolah modern Itu dapat berdampak tidak baik terhadap anak-anak wanita sekolah sekolah wanita diletakkan di bawah pengawasan dan pengelolaan ulama dan dengan demikian terpisah dari Kementerian Pendidikan.

Pendidikan Islam tradisional bagi laki-laki difokuskan untuk membentuk calon calon anggota dewan ulama kurikulum untuk sekolah Islam tradisional juga sebagai menggunakan kurikulum pendidikan umum tetapi fokusnya pada studi

Islam dan bahasa Arab untuk pendidikan agama dilakukan di bawah supervisi dari Universitas Islam Imam Saud atau Riau dan Universitas Islam Madinah atau Madinah Namun demikian di universitas-universitas umum pelajaran agama Islam 
merupakan mata kuliah wajib apapun jurusan yang diambil mahasiswa.

Adapun pendidikan tinggi atau universitas di Arab Saudi terbagi menjadi dua bagian utama yakni pendidikan agama dan pendidikan umum Namun demikian sekarang sudah sangat banyak universitas yang menggabungkan keduanya jenis perguruan tinggi Arab Saudi adalah universitas Institut untuk perempuan atau college for women Institut Administrasi Publik atau Institute of public administration dan Institut ke guruan atau teachers training college semua universitas berada di bawah supervisi kementerian pendidikan tinggi atau Ministry off education kecuali Universitas Islam Madinah atau Islamic University of Madinah universitas terbaik di Arab Saudi untuk pendidikan agama Islam yang berada di bawah supervisi dewan menteri atau Council of ministers untuk memasuki perguruan tinggi di Arab Saudi calon mahasiswa harus memenuhi tes masuk perguruan tinggi atau general secondary education certificate examination atau tawjihi.

Untuk pendidikan tinggi Universitas tingkatannya sama seperti Universitas pada umumnya yaitu Strata 1 atau Bachelor strata 2 atau Master strata 3 atau Doctor untuk S1 waktu yang dibutuhkan adalah 4 tahun minimal tetapi untuk teknik medis dan informasi dibutuhkan minimal 5 tahun untuk menyelesaikannya untuk S2 atau Master dibutuhkan minimal dua tahun untuk menyelesaikannya dengan syarat harus sudah menyelesaikan S1.

Ada dua jalur untuk S2 dengan tesis atau By thesis maka setelah menyelesaikan mata kuliah yang ditentukan kita harus menyelesaikan tesis kurang 


\section{Didin Sirojudin, Waslah.}

lebih selama 1 tahun atau 2 semester Sedangkan untuk jalur kuliah kita hanya perlu menyelesaikan seluruh mata kuliah yang telah ditentukan namun dengan jumlah mata kuliah yang lebih banyak.

Untuk S3 lama waktu yang dibutuhkan adalah 3 tahun setelah menyelesaikan S2 untuk S3 kita harus menyelesaikan mata kuliah dan mengumpulkan disertasi yang merupakan hasil riset independen yang telah dilakukan Selain itu tambahan syarat kadang-kadang diperlukan seperti Minal mempublikasikan jurnal internasional atau konferensi internasional Sebagai tambahan ada beberapa Universitas khusus untuk perempuan yang sebagian besar berfokus pada ilmu pendidikan jenjang yang tersedia untuk manajemen penjaminan mutu perguruan tinggi di Indonesia .

Universitas besar Arab Saudi diantaranya King Saud University University of Petroleum dan mineral King Abdul Aziz University University Universitas King Abdullah University of teknologi (KAUST).

\section{PENUTUP}

Dibawah pengaruh kebudayaan modern, sistem sekolah-sekolah dasar, menengah, sekolah-sekolah kejuruan, sekolah-sekolah teknik, dan sampai pada sistem universitas yang ada di Arab dan dunia Islam diperbaharui dan disesuaikan menurut pola barat begitu juga halnya penyusunan silabus dan kurikulum. Pengadaptasian yang dimaksud disini adalah disini bukanlah berarti menelan 
mentah-mentah segala apa yang dari barat, tetapi sistem dan bentuk pendidikan barat yang maju yang disesuaikan dengan falsafah pendidika islam.

Dalam upaya pembangunan nasional, sistem pendidikan dibebani 3 tujuan :

(1) untuk memberika sekurang-kurangnya pendidikan dasar bagi seluruh penduduk,

(2) untuk dari mempersiapkan siswa-siswa dengan berbagai keterampilan yang diperlukan untuk pengembangan ekonomi yang terus berubah, (3) untuk mendidik anak-anak dalam kepercayaan, praktek, nilai-nilai serta kebudayaan islam.

\section{E. DAFTAR PUSTAKA}

Azyumardi Azra, Pendidikan Islam Tradisi dan Modernisassi Menuju Milenium baru Jakarta : Logos, 1999 .

Agustiar Syah Nur, Perbandingan Sistem Pendidikan 15 Negara( Bandung: Lubuk Agung: 2001).

Alan Richards, Higher Education in Egypt. Jurnal Education and Human Resources Vol. 20 no.1 tahun 2013 hal 14-36.

Belgrami, hamid Hasan, dan Ali Said Asyraf 1989 The conseft Of University terj. Machnun Husen. Yogyakarta : Tiara Wacana.

Cyril Poster, Gerakan Menciptakan Sekolah Unggulan, (Jakarta : Lembaga Indonesia Adidaya, 2000), Cet. Ke-1.

Agustiar Syah Nur, Perbandingan Sistem Pendidikan 15 Negara( Bandung: Lubuk Agung: 2001).

Arja Haapakorpi, assurance Processes in Finnish Universities. Jurnal Quality in education Vol.17 no.1 tahun 2011.hal 70-82.

E.Constatinides. and M.C.Zinck Potential of the social media as intrumens of higher education marketing: A segmentation study. Jurnal Of Marketing For Higher Education. Vol.21. No.1 tahun 2011.

Komisi Nasional Mesir untuk UNESCO,Sumbangan Islam Kepada Ilmu dan kebudayaan (Bandung:Pustaka, 1997). 


\section{Didin Sirojudin, Waslah.}

Mahmud Yunus, Kamus Arab Indonesia, (Jakarta : (Bandung : Al-Ma'arif, 1984), h. 110.

Muhammad Munir Mursy Ushuliha wa Tatahwuriha fi al-Bilad al-Arabiyyat Al-Qohirah: 'Alim al-Kubt, Jurnal al-Tarbiyyat la-Islamiyyat: Vol.20. No 1 Tahun 2013.hal.21-40.

John M. Echolis, Hasan Shadily, Kamus Inggris Indonesia, (Jakarta : Gramedia, 1988) Cet. Ke XVI, h. 460.

Lukman Ali, Kamus Besar bahasa Indonesia, (Jakarta : Balai Pustaka, 1995), Cet. Ke-4, h. 677.

Louisa Loveluck, Education in Egyft ; Key Challenges.(London: Chatham house 2012).

M.N. Nasution, Manajemen Mutu terpadu, (Jakarta : Ghalia Indonesia, 2004), Cet. ke-3, h.15.

Philip K Hitti, History Of the Arab, (London: The Macmilan Press LTD,1974).

Ramayulis,Ilmu Pendidikan Islam, (Jakarta: Kalam Mulia, 2011).

Imdadun rahman, Arus baru radikal Islam:Tranmisi Revivalisme Islam Timur tengah ke Indonesia,(Jakarta: Erlangga, 2009).

Retno wilan damayanti:Quality award untuk menngevaluasi Pencapaian Implementasi Manajemen KualitasPerusahaaan. Jurnal Peforma Vol.7 No.1 tahun 2008. Hal.55-70.

UNESCO Institute for Statistics, Global Education Digest 2010:Comparing education statistic Across The World, (Canada: UNESCO Institute For statistics, 2010).

Waslah. "Manajemen Madrasah Bertaraf Internasional Amanatul Ummah Pacet Mojokerto", dalam Jurnal Dinamika : Jurnal Kajian Pendidikan dan Keagamaan, Vol. 3, no. 1, 87-96, 2018. 